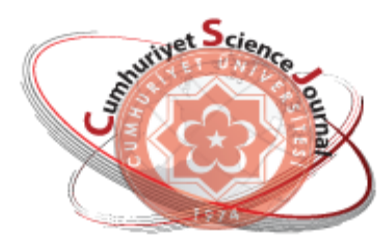

e-ISSN: $2587-246 X$

ISSN: $2587-2680$

\section{Enmanoryet Seienee Journal $\cos$}

Cumhuriyet Sci. J., Vol.40-4 (2019) 896-901

\title{
A Dynamic Network Model For Population Growth And Urbanization
}

\author{
Emir HALİK $\dot{I}^{*}$ \\ ${ }^{1}$ EgeUniversity, Faculty of Science, Department of Physics, Izmir, Turkey
}

Received: 14.10.2019; Accepted: 08.12.2019

http://dx.doi.org/10.17776/csj.632996

\begin{abstract}
Dynamic networks imply those states of which change over time and such changes are generally associated with the topology of a network. Dynamic models are currently needed for numerous systems which could be defined as a network model. Those related to the propagation of living organisms are also a typical example. The study has examined a sample space which has been defined in the network topology of human population as the way in which it will spread with population growth and correlated with various variables in the modeled dynamic network.
\end{abstract}

Keywords: Network, Population growth, Logistic differential equation, Connected component, Clustering coefficient, Correlation.

\section{Nüfus Artışı ve Kentleşme İçin Dinamik Bir Ağ Modeli}

Özet. Dinamik ağlar, zaman içinde değişiklik gösteren durumları belirtmekte ve bu değişiklikler genellikle bir ağın topolojisi ile ilişkilendirilmektedir. Ağ modeli olarak tanımlanabilecek birçok sistem için dinamik modellere ihtiyaç duyulmaktadır. Canlı organizmaların yayılması ile ilgili olanlar da bu duruma bir örnektir. Çalışmada insan nüfusunun ağ topolojisi tanımlanarak ile bir örnek uzay oluşturulmuş, nüfus artışı ile içerisinde nasıl bir yayılma görüleceği araştırılmış ve nüfus büyümesinin modellenen dinamik ağdaki çeşitli değişkenler ile aralarındaki korelasyonlar incelenmiştir.

Anahtar Kelimeler: Dönüştürülmüş iki boyutlu dağılım, Bağımlılık, İki boyutlu dağılım, Spearman sıra korelasyonu, Fréchet sinırları.

\section{INTRODUCTION}

When the human population was still small and when people were constantly moving from one place to another, the abandonment of the land on which they grew plants and lived was not a problem for the nature yet. However, the idea that nature had to be conquered developed later and people pass on to expansionist form of life [1]. By far the most important factor in this sense originated from the transition to settlement. So sufficient was settlement instead of immigration for sources that existing land was preserved with inevitable expansion to the new soils. It is known that Neolithic people first passed to settlement approximately 12500 years ago [2,3]. It was the major factors which played a significant role in the related transition that agricultural development, climatic changes and husbandry of animals occurred. Although it is still obscure whether those reasons triggered population growth or population growth lead to those reasons, it is a fact that population growth accelerated use up of present sources in a place and necessitated people to expand to new lands, which is currently going on. 
Expansion of regions by human being under the settlement principle has caused the cities to be made up of districts and countries to be composed of cities [4]. Increasingly growing population and urbanization leads to construction shifting to rural areas and expansion is in the form of construction across natural zones by transforming them into increased settlement. Various predictions and dynamic models have been thus far developed on the growth and spread of countless plant and animal populations $[5,6]$ while those on spreading human population are far cry from being sufficient $[7,8]$.

The present study has modeled the human expansion accompanied by population growth using a network model to finally examine its correlation of several variables with it. A fictitious region has been defined, separated into a certain number of nodes and a precessor pattern is created in such a way that no nodes are connected with each other (disconnected graph) first and then a random starting node has been selected where the population first began to proliferate and urbanized in a sense with the identification of the location and linking a new node to the preceeding ones over time. In conclusion, the correlation between population growth and some characteristics of the growing network has been shown and the conclusions presented in the section of results and discussion.

\section{MATERIALS AND METHODS}

A population-related differential equation to indicate the two important concepts namely, ecology and epidemiology are as follows;

$$
\dot{N}=(r-d) N,
$$

where $N$ is the number of individuals $r$ birth rate and $d$ death. If $r>d$ the population continues to grow indefinitely. In a real environment, any growth in the population will hit constraints such as in running out of nutrients or physical space, which suggests the concept of carrying capacity and a more proper population growth could be given by the logistic equation [9] below;

$$
\dot{N}=r N\left(1-\frac{N}{\kappa}\right)
$$

where $\kappa$ is the carrying capacity. When $N$ increases, the rate of growth decreases. As $N=\kappa$, growth of the population stops. For any initial population $N_{0}$, solution of eq. 2 is presented as follows;

$$
N(t)=\frac{\kappa N_{0} e^{r t}}{\kappa+N_{0}\left(e^{r t}-1\right)}
$$

with $N_{0}$ being the initial population. As time passes, the population converges to its carrying capacity. Once it has reached it, growth stops. However, there may be occasional dynamic limits for the carrying capacity [10]. Ecological carrying capacity is suitable for non-human beings whereas it does not always apply to human beings, because economy, environment, culture and demography are involved [11]. Nevertheless, an average carrying capacity can be determined in order to acquire fundamental approaches to population dynamics $[12,13]$.

The region of population distribution in the developed model as a pattern composed of 36 nodes, each of which corresponds to a zone likely to be occupied on a possible settlement map. The network growth has been defined as expanding 2-D graph distribution which represents a graph with $n$ nodes uniformly distributed over a plane. Edges between nodes have been determined by distance $d$. The simulation exhibits that the $d$ value in the network changes proportionally with the increasing population by the continuous logistic equation. The initial population for population growth model is 100 individuals and 
the growth rate $(r)$ 0.3. The carrying capacity corresponding to the situation where all the spread on the system is completed is limited to a hundred thousand. Moreover, one has calculated the global clustering coefficient (GCC) and the largest connected component (LCC) values of the cluster at each moment corresponding to the time checkpoints of the continuous logistic equation in the growing network as a 2D graph distribution. The LCC represents the largest subset in a network [14] (reaches the total number of nodes in the network with each node having a connection), while the GCC, a measure of how much the network is connected, is the ratio of three-fold number of the triangles to that of pairs of adjacent edges in network [15]. GCC and LCC in network growth have been simulated by averaging over ten thousand experiments to reduce possible errors statistically. Figure 1 has shown the edges between nodes in the growing network at various timesteps (given checkpoints) selected from a random experiment.

a)

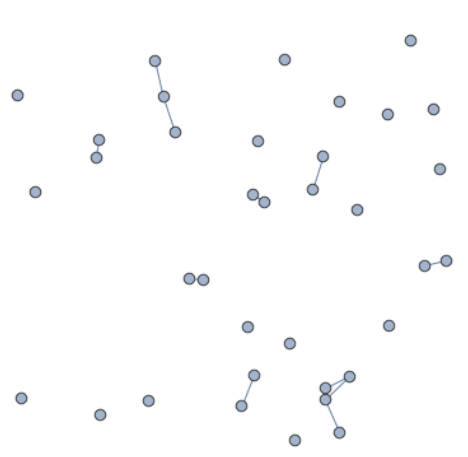

b)

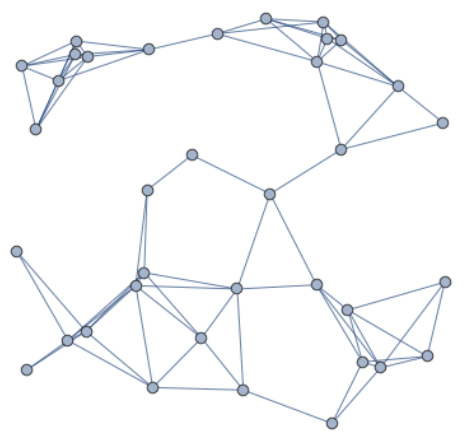

c)

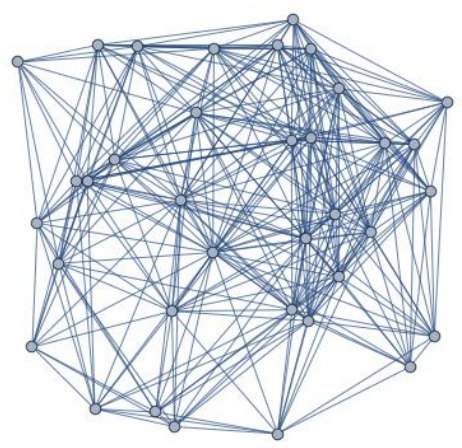

Figure 1. Three snapshots of the growing network which has a) $d=0.07$, b) $d=0.22$, c) $d=0.49$.

The aforementioned times correspond to steps of 0.01 for $d$ values with figure 2 exhibiting the graph of the GCC values versus time and logistic population growth $(N)$ versus time. Note that the logistic population growth data have been normalized to the $[0,1]$ range where 1 is the carrying capacity.

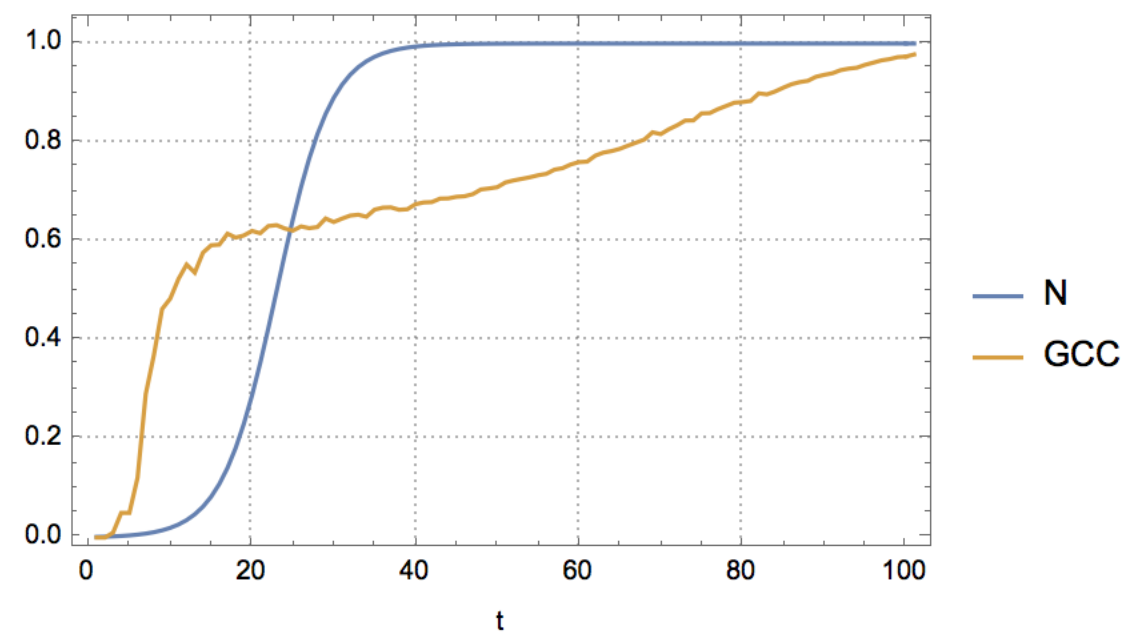

Figure 2. Behaviors of the population and the global clustering coefficient over time. When the population reaches to carrying capacity, the number of edges of the network is observed to be still increasing.

When the population reaching to the carrying capacity, the reason for the growth of the GCC is that the number of connections of each node increases due to the rise of the connection distance in the 2-D graph distribution model. Accordingly, the increase of LCC in the growth of the network over time is presented in figure 3. 


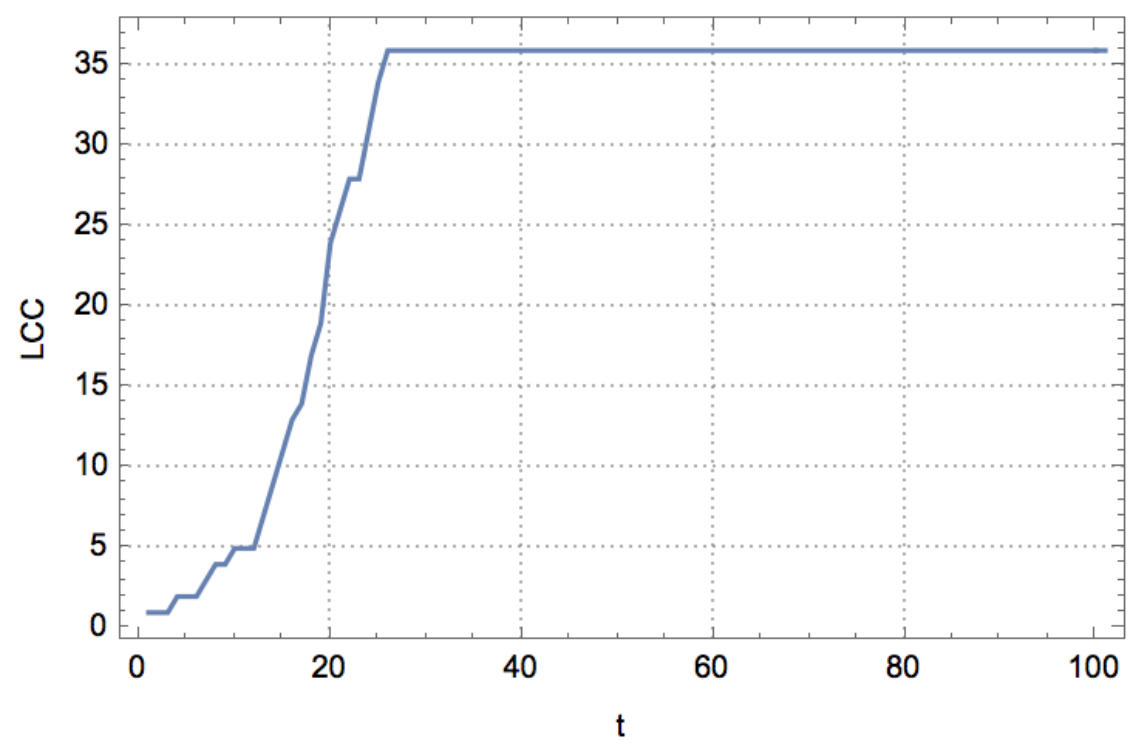

Figure 3. Growth of the largest connected component of the network. After the 26th timestep, the network has been fully connected.

Following a given period of time, the logistic growth of the population has reached to carrying capacity, the LCC value to the maximum number of nodes and the GCC to its maximum of 1 , which exhibits the way the population growth and the GCC and LCC of the network correlate with the generated model. Pearson correlation coefficient [16] between two variables is given as;

$$
\rho_{X Y}=\frac{\sigma_{X Y}}{\sigma_{X} \sigma_{Y}}
$$

where $\sigma_{X Y}$ is the covariance between variables $X$ and $Y$ and the denominator is also their multiplied standard deviations. Each of three variables' Pearson correlation coefficients with the other two has thus been calculated and shown in Table 1.

Table 1. Pearson correlation coefficients.

\begin{tabular}{|c|c|c|}
\hline$N$-GCC & $N$-LCC & GCC-LCC \\
\hline 0.793 & 0.958 & 0.801 \\
\hline
\end{tabular}

\section{RESULTS AND DISCUSSION}

With a certain population growing, the interconnectedness of each region spread over time is also seen in such concepts as online social, spread disease and traffic networks [17-19]. Therefore, the three quantities examined in the established model are correlated with each other. LCC is highly correlated with population growth in simulation outputs. The reason for the very strong relationship between them is the increase in LCC in a behavior similar to the population in spreading from one node to the other with population growth. On the other hand, as the population grows and spreads to other nodes, the number of connections between the nodes increases. For instance, open triplets turn into closed triangles, which has been simulated in such a way that interactions have increased between settlements as the population grows in the model. That is the explanation for the strong relationship between $N$ and GCC. The strong relationship between the GCC and the LCC is also one of the basic networking features requiring that the growth of the connected component should depend on the number of connections, ie the clustering 
coefficient [20]. They have become well correlated since the network grew from a single point in the 2D graph distribution-based model.

The present knowledge of the world is often determined by geographical maps. In the developed model, a possible settlement on a given map has been divided into units (nodes) and extrapolated from the initial node to the others with the population. In order that the model to should show some similarity to the reality, the number of connections has continued to increase even if the carrying capacity has been reached in order to make the settlement area completely connected to each other. If different components of a human population is to have heterogeneous requirements, estimates of total carrying capacity based on a single formula could not be accurate. Similarly, it is possible that different parts of the global human population would have heterogeneous needs as well. Therefore, the developed model may seem to be simplified in terms of the increase of the human population and its limitation to a certain area. However, in future studies, carrying capacity, a variable of equations such as logistic growth, could be rendered more dynamic by having multiple variables within itself.

\section{REFERENCES}

[1] Goudie A. S., Human impact on the natural environment, 8th ed., Wiley: Hoboken, NJ, USA, 2018.

[2] Kuijt I. J., People and space in early agricultural villages: exploring daily lives, community size, and architecture in the Late Pre-Pottery Neolithic, Anthropol. Archaeol., 19 (2000) 75-102.

[3] Putterman L., Agriculture, diffusion and development: ripple effects of the neolithic revolution, Economica, 75 (2008) 729-748.

[4] Dickinson R. E., City and region: a geographical interpretation, Taylor\&Francis: Oxfordshire, UK, 1998.

[5] Clark J. S., Lewis M., McLachlan J. S., HilleRisLambers J., Estimating population spread: what can we forecast and how well?, Ecology, 84 (2003) 1979-1988.

[6] Haydon D. T., Morales J. M., Yott A., Jenkins D. A., Rosatte R., Fryxell J. M. P., Socially informed random walks: incorporating group dynamics into models of population spread and growth, Roy. Soc. B. Biol. Sci., 275 (2008) 1101-1109.

[7] Wittemyer G., Elsen P., Bean W. T., Burton A. C. O., Brashares J. S., Accelerated human population growth at protected area edges, Science, 321 (2008) 123-126.

[8] Bongaarts J., Human population growth and the demographic transition, Philos. T. Roy. Soc. B., 364 (2009) 2985-2990.

[9] Nowak M. A., Evolutionary dynamics, Harvard University Press: London, UK, 2006.

[10] Meyer P. S., Ausubel J. H., Carrying capacity: a model with logistically varying limits, Technol. Forecast. Soc., 61 (1999) 209-214.

[11] Cohen J. E., Population growth and earth's human carrying capacity, Science, 269 (1995) 341-346.

[12] Graymore M. L., Sipe N. G., Rickson R. E., Sustaining human carrying capacity: a tool for regional sustainability assessment, Ecol. Econ., 69 (2010) 459-468.

[13] Hopfenberg R., Human carrying capacity is determined by food availability, Popul. Environ., 25 (2003) 109-117.

[14] Yang X., Megson G. M., Tang Y. Y., Xing Y., Largest connected component of a star graph with faulty vertices, Int. J. Comput. Math., 85 (2008) 1771-1778. 
[15] Soffer S. N., Vazquez A., Network clustering coefficient without degree-correlation biases, Phys. Rev. E., 71 (2005) 057101.

[16] Benesty J., Chen J., Huang Y., Cohen I., Pearson correlation coefficient. In Noise reduction in speech processing, Springer: Berlin, Heidelberg, 2009.

[17] Centola D., The spread of behavior in an online social network experiment, Science, 329 (2010) 1194-1197.

[18] Jeger M. J., Pautasso M., Holdenrieder O., Shaw M. W., Modelling disease spread and control in networks: implications for plant sciences, New Phytol., 174 (2007) 279-297.

[19] Coclite G. M., Garavello M., Piccoli B., Traffic flow on a road network, SIAM J. Math. Anal., 36 (2005) 1862-1886.

[20] Serrano M. Á., Boguná M., Percolation and epidemic thresholds in clustered networks, Phys. Rev. Lett., 97 (2006) 088701. 